\title{
Una reflexión en torno al Seminario sobre la Reforma del Estado: «La organización territorial interna de las Comunidades Autónomas»
}

\author{
Patricia González Pulido \\ Doctorando de la Universidad de Alcalá de Henares \\ pgpulido@yahoo.es
}

Uno de los problemas jurídicos más relevantes de nuestro modelo de Estado, a los que aún no se ha sabido dar una respuesta esclarecedora, está relacionado con su articulación organizativa. España, como país configurado políticamente de manera descentralizada, se organiza en tres niveles territoriales, que requieren, todos y cada uno de ellos, de una estructura determinada, y que en la práctica supone la heterogeneidad, originando desigualdades dentro del territorio nacional.

La presente reflexión surge en el contexto del Seminario sobre la Reforma del Estado celebrado el 30 de noviembre de 2016 en el Instituto de España en Madrid. En esta ocasión el tema tratado fue «La organización territorial interna de las Comunidades Autónomas». En la sesión intervinieron como ponentes: D. José Luis Carro Fernández-Valmayor, D. Tomás de la Quadra-Salcedo Fernández del Castillo, D. Avelino Blasco Esteve, D. Martín Razquín Lizarraga y D. Francisco Delgado Piqueras, quienes fueron presentados y moderados por D. Santiago Muñoz Machado. En concreto, la temática del Seminario se centró principalmente en la problemática que supone la articulación de todos los niveles del Estado, prestando especial atención a la provincia, la Diputación, los entes locales y los nuevos entes territoriales intermedios que están surgiendo, como las veguerías en Cataluña, o los Consejos Insulares en las Islas Baleares. Las cuestiones a las que se intentaron dar respuesta a lo largo de la jornada planteaban dudas sobre, ¿cuáles son los problemas actuales de las provincias?, ¿qué papel desempeñan las diputaciones?, ¿hacia dónde se dirige la autoorganización de los entes territoriales?

Las siguientes líneas recogen las principales ideas que se expusieron y debatieron en esta sesión. El punto de partida ineludible es la Constitución española (CE), que recoge en su Título VIII la organización territorial del Estado. El artículo 137 CE dispone de forma genérica que los municipios, provincias y Comunidades Autónomas configuran la organización territorial del Estado, dotándoles de autonomía para gestionar sus propios intereses. Encontramos una organización presentada en tres niveles territoriales obligados a coordinarse para lograr un óptimo funcionamiento de los mismos. La autonomía de la que gozan los distintos territorios particulariza las condiciones de las que disfrutan cada uno de los ciudadanos, afectando a la homogeneidad de Derechos en el mismo territorio nacional. Igualmente, los artículos 140 y 141 CE ponen de manifiesto la autonomía de los entes locales. No debemos olvidar cómo la sentencia dictada por el Tribunal Constitucional (STC) 32/1981, de 28 de julio, presenta al principio de autonomía como «uno de los principios estructurales básicos de nuestra Constitución».

Uno de los conceptos más debatidos durante el Seminario fue el referente a la autoorganización del territorio

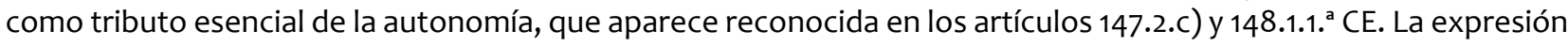
«instituciones de autogobierno», que contienen los citados artículos, puede adoptar cuatro significados o variantes, tal y cómo explicó D. José Luis Carro. En primer lugar, entender las instituciones políticas como fundamentales al amparo del artículo $151 \mathrm{CE}$, siendo totalmente innecesario porque ya se encuentran recogidas en el artículo 150 CE. En segundo lugar, atender a las instituciones autónomas propias del artículo 147.2 CE, previstas ya en el Estatuto de Autonomía. En tercer lugar, instaurar instituciones que no se encuentran previstas en el Estatuto de Autonomía, lo que supone una práctica de imposible o difícil ejecución. Estas tres variantes demuestran que el artículo 148 CE tiene un carácter transitorio, ya agotado y, por tanto, superfluo. En cuarto y último lugar, identificar 
la competencia prevista en muchos Estatutos de Autonomía sobre creación y organización de su propia Administración, constituyendo así una competencia declarativa. La concurrencia de muchos artículos constitucionales, y la superfluidad de muchos de ellos, pone de nuevo sobre la mesa la exigencia de una revisión de nuestro Texto constitucional.

Dada la singularidad del modelo español y del espacio autonómico que nos acontece, el mayor problema que se plantea radica en la actuación de competencias estatales y autonómicas que se ejercen sobre la configuración local, donde la conflictividad es permanente al no haberse optado por un modelo autonómico competencial más explicativo. La autonomía local, garantizada constitucionalmente, no puede verse constreñida a la actuación estatal por un motivo comunitario o estatal por dos razones. En primer lugar, la Carta europea de la autonomía local de 1985, ratificada por España en 1988, dispone en su artículo 3 el concepto de autonomía local, estableciendo que "por autonomía local se entiende el derecho y la capacidad efectiva de las entidades locales de ordenar y gestionar una parte importante de los asuntos públicos, en el marco de la ley, bajo su propia responsabilidad y en beneficio de sus habitantes». En segundo lugar, atendiendo al artículo 149.1.18 CE, al Estado le corresponde la competencia exclusiva de establecer las bases del régimen jurídico de las Administraciones Públicas, es decir, fijar la legislación básica a partir de la cual las Comunidades Autónomas (artículo 148.1.2 CE), a través de sus Estatutos de Autonomía, podrán asumir competencias en materia de régimen local. La regulación de los entes locales vuelve a recordarnos, en términos del Tribunal Constitucional, su carácter bifronte. La organización autonómica se encuentra en situación de dependencia de la competencia versátil del Estado, lo que conllevaría a exigir una participación del ente regional en la legislación básica dictada por el Estado.

Aunque la autonomía es otorgada a las provincias por vía de los artículos 137 y 141 CE, la entidad territorial básica puesta en cuestión es la provincia. La rigidez en su propia organización es la principal problemática, que viene explicada por su historia, es decir, en el momento de creación de nuestro sistema constitucional no disponíamos de un modelo determinado de Estado, utilizando a la provincia de asidero organizativo. Esta situación se ha mantenido en el tiempo produciendo el bloqueo organizativo actual que sufre el Estado español.

La provincia, entendida como entidad con personalidad jurídica propia y determinada por la agrupación de municipios, no le puede ser negada su carácter de ente local, donde su gobierno y administración se encomienda a la Diputación. En virtud del artículo 141.2 CE no debemos entender a la provincia como una mera Administración, sino que su reconocimiento constitucional (artículo $137 \mathrm{CE}$ ) pone de manifiesto que forma parte de la estructura esencial de la organización del Estado, dotada de autonomía y legitimidad democrática. La Constitución no delimita en ningún momento el número de provincias, dando lugar a construcción de ideas que abogan porque una Comunidad Autónoma pluriprovincial se convierta en otra uniprovincial, situación compleja que no encaja en el supuesto de hecho existente. El cambio procedería de una manifestación competencial por parte del poder constituyente. La posibilidad constitucional de crear entes territoriales propios distintos a la provincia (artículo 141. 3 CE), plantea la posibilidad de crear entes territoriales intermedios, como ya existen en algunas Comunidades Autónomas. Asimismo, en muchas ocasiones las propias Comunidades Autónomas han puesto en cuestión el papel de la provincia, a pesar de que el propio ente regional puede descargar la prestación de servicios en esta última en virtud de no crear duplicidad administrativa. El embate a la provincia, junto con las leyes de transferencia de competencias a las Diputaciones, hizo que la STC 32/1981, de 28 de julio y posterior STC 109/1998, de 21 de mayo, recordasen que hay un mínimo de competencias provinciales que no pueden quedar vacías.

Aunque los Pactos Autonómicos de 1981 y 1992 se dirigieron a lograr esclarecer el problema organizativo y competencial de nuestro Estado autonómico, realmente lo que instauraron fue un mayor desconcierto en nuestro ordenamiento jurídico. Podemos destacar la Comunidad Autónoma andaluza, que ha ido mermando competencias de las Diputaciones; sin embargo, la Comunidad Autónoma Vasca reconoce Derechos Históricos a sus Territorios Forales. Tras la aprobación de la Ley 27/1983, de 25 de noviembre, de Relaciones entre las Instituciones comunes de la Comunidad Autónoma y los órganos forales de sus Territorios Históricos, se pone sobre la mesa el debate de si las competencias deben recaer en mayor proporción sobre la Comunidad Autónoma o sobre los Territorios Forales. No se debe olvidar que la Disposición Adicional Primera CE ampara y respeta los Derechos Históricos de los Territorios Forales.

El incremento o detrimento de las competencias otorgadas a las Diputaciones se encuentran influidas en muchas ocasiones por el panorama político del momento. No debemos olvidar la posición que ocupan los partidos políticos, debido a que son los principales protagonistas que no se muestran a favor de ceder potestades a la Diputación, por el temor que supone la posible aparición de representaciones que disputen el poder en su propio territorio, a través de la creación de administraciones periféricas. Asimismo, la posición mediática que ocupan las Diputaciones es más que evidente; cuestiones tales como la corrupción, la falta de legitimidad democrática o el gasto excesivo de las mismas suponen la creación de una desafección política y ciudadana hacia las Diputaciones. 
Atendiendo a la realidad española, donde existen más de 8.000 municipios, las Diputaciones siguen siendo necesarias en el panorama español porque son las vías de resolución de problemas más próximas a los municipios, y por ende a los ciudadanos. Asimismo, la organización territorial española ha dado lugar a dos visiones; la primera, una visión tecnocrática que aboga por la supresión de municipios; y la segunda, una visión democrática, donde ya la Constitución española de 1812 preveía que debía haber una institución política allí donde radicasen los ciudadanos.

A pesar de las disputas surgidas en torno a las Diputaciones, el artículo 31.2 de la Ley $7 / 1985$, de 2 de abril, Reguladora de las Bases del Régimen Local, dispone que son fines propios y específicos de la provincia garantizar los principios de solidaridad y equilibrio intermunicipal. Principios que asignan a la Diputación la potestad de coordinar, cooperar y alcanzar la igualdad entre municipios. La provincia, actuando como conector entre el Estado y Comunidad Autónoma, y esta con el municipio, se consolida como ente sobre el que pivota el conjunto de políticas nacionales, autonómicas y locales.

La aprobación de la Ley 27/2013, de 27 de diciembre, de racionalización y sostenibilidad de la Administración Local, ha supuesto un vaciamiento de competencias municipales en favor de la Diputación, lo que ha dado lugar a las recientes SSTC 41/2016, de 3 de marzo de 2016, y 111/2016, de 9 de junio de 2016, donde se vuelven a poner de manifiesto los principios de autonomía local, democrático, lealtad institucional y autonomía financiera.

En la práctica podemos observar cómo las ciudades de mayor tamaño y, por tanto, con superior capacidad y eficiencia económica, los principios de solidaridad y equilibrio intermunicipal no se hacen tan visibles. La prestación de servicios básicos no supone gran problema, al contrario que a los pequeños municipios, donde el acceso a prestaciones de primera necesidad se ve, en algunas ocasiones, interrumpida. Situación que vuelve a poner de manifiesto la necesidad de la existencia de la Diputación o, en su caso, como se viene debatiendo, la creación de entes territoriales intermedios coordinadores de servicios públicos de carácter local.

Una parte importante del Seminario se centró en plantear la posible creación y existencia de entidades territoriales intermedias en general. En particular, se expuso como ejemplo representativo de estas figuras los Consejos Insulares de las Islas Baleares, en cuanto su configuración, naturaleza jurídica y funciones más representativas.

El Consejo Insular constituye una de las principales entidades intermedias en el panorama español y, por tanto, pieza esencial en el organización de la Comunidad Autónoma. Sin entrar a valorar la organización y articulación de la institución, lo que me interesa destacar radica en las competencias que le han sido atribuidas. El Estatuto de Autonomía de las Islas Baleares de 2007 y el anterior del año 1983, reconocían la autonomía de los Consejos, atribuyéndoles la representación, el gobierno y la administración de las Islas; además de ostentar la ejecución de un gran número de competencias, en un principio propias de la Diputación, que se han visto incrementadas exponencialmente. Este aumento de competencias, propias del Consejo Insular, produce la propia inejecución de la Comunidad Autónoma, situación que provoca una descentralización del poder ejecutivo, que se encuentra compartido entre el gobierno del ente regional y el Consejo Insular. La presente previsión goza de garantía constitucional al encontrarse recogida en el Estatuto de Autonomía de las Islas Baleares, con ello podemos observar cómo el Consejo se encuentra en una posición equivalente y, no inferior, con respecto a la Comunidad Autónoma, equiparándose en los poderes normativos que ostentan. La presente situación pone de manifiesto cómo el Estatuto balear de 2007, como Estatuto de segunda generación, apuesta por la autonomía de la región frente al Estado central, haciendo valer su posición de autogobierno a través de la Comunidad Autónoma, pero sin olvidar a los Consejos Insulares que conforman, junto con otras instituciones, la organización del ente regional.

Que los Estatutos de Autonomía propicien la creación de entes distintos a la provincia como los anteriores Consejos Insulares o las veguerías en Cataluña, no significa que favorezcan la desaparición de la misma. El artículo 90 del Estatuto de Cataluña dispone que la veguería es el ámbito territorial específico para el ejercicio del gobierno intermunicipal de cooperación local, con personalidad jurídica propia. La interpretación que realiza el Estatuto catalán hace que reflexionemos sobre la posible eliminación de las provincias y sus correspondientes Diputaciones, que serán sustituidas por el Consejo de Veguería. Atendiendo a la STC 31/2010, de 28 de junio, el Tribunal constitucional ha declarado a las veguerías constitucionales, pero sin olvidar que «[...] la veguería podría no ser una nueva entidad local, sino la nueva denominación de la provincia en Cataluña (.../...) La veguería reúne en el Estatuto los caracteres típicos de la provincia y es ésta, más allá de su denominación específica, la institución constitucionalmente garantizada. Nada se opone, por tanto, a que, a efectos estrictamente autonómicos, las provincias catalanas pasaran a denominarse veguerías» (FJ 41). Igualmente, nada impide que los «Consejos de veguería sustituyeran a las Diputaciones provinciales, pues el art. 141.2 CE prescribe que el gobierno y la administración autónoma de las provincias han de encomendarse a Diputaciones u otras Corporaciones de carácter representativo (.......) De sustituir los Consejos de veguería a las Diputaciones corresponderá a la legislación del Estado determinar su com- 
posición y el modo de elección de sus miembros, correspondiendo también a la normativa básica estatal regular sus competencias en el orden local» (FJ 41).

El surgimiento de nuevos entes intermedios parece que viene a sustituir a la provincia. A pesar de la teoría jurídica de estos entes, no podemos obviar que nuestra Constitución sitúa a la provincia como entidad local necesaria e imprescindible, cuya existencia y autonomía está garantizada constitucionalmente. Por tanto, independientemente del ente intermedio que ocupe el tercer nivel, ya sea provincia, veguería o Consejo Insular (o como quieran denominarlo las Comunidades Autónomas que lo creen), se debe proporcionar una mayor flexibilidad por parte del legislador ordinario en relación con la organización territorial, con el fin último de constituir un sistema capaz de prestar servicios de calidad al conjunto de ciudadanos. 